\title{
Histomorphological Profile of Colonoscopic Biopsies and Pattern of Colorectal Carcinoma in Kavre District
}

\author{
Rajbhandari M, ${ }^{1}$ Karmacharya $A,{ }^{2}$ Khanal K, ${ }^{3}$ Dhakal $P^{1}$, Shrestha $R^{4}$
}

\author{
${ }^{1}$ Department of Pathology \\ ${ }^{2}$ Department of Surgery \\ ${ }^{3}$ Department of Community Medicine \\ ${ }^{4}$ Department of Pharmacology
}

Dhulikhel Hospital- Kathmandu University Hospital Kathmandu University School of medical Science

Kavre, Dhulikhel

\section{Corresponding Author}

Merina Rajbhandari

Department of Pathology

Dhulikhel Hospital- Kathmandu University Hospital Kathmandu University School of medical Science

Kavre, Dhulikhel

Email: rajbhandarimerina@hotmail.com

\section{Citation}

Rajbhandari M, Karmacharya A, Khanal K, Dhakal P, Shrestha R. Histomorphological Profile of Colonoscopic Biopsies and Pattern of Colorectal Carcinoma in Kavre District. Kathmandu Univ Med J 2013;43(3):196-200.

\section{ABSTRACT}

\section{Background}

Colonoscopy is the method to visualize the mucosa of the entire colon and terminal ileum to detect the intestinal abnormalities and obtain biopsy for definitive diagnosis. For clinical decisions in the diagnosis of various colonic lesions unambiguous interpretation of colorectal biopsies is necessary.

\section{Objectives}

To assess the prevalence pattern of colonic diseases and to correlate the incidence of colorectal carcinoma with age, sex, site and symptoms presented at Dhulikhel Hospital.

\section{Methods}

The materials consisted of 126 biopsies which were submitted to the Department of Pathology, Kathmandu University School of Medical Sciences, Dhulikhel, during the period of July 2011- July 2012 .Data collected and entered in MS-Excel and were analyzed using SPSS-16.

\section{Results}

Out of 126 colonoscopic biopsies 34(27\%) showed chronic nonspecific inflammation, followed by carcinoma $25(19.8 \%)$, non-neoplastic polyps $21(16.7 \%)$, granulomatous inflammation $14(11.1 \%)$, neoplastic polyps $8(6.3 \%)$, ulcerative colitis 4(3.2\%) Miscellaneous lesions; Acute focal colitis, Eosinophilic colitis were also observed in 19 (15.1\%). A higher frequency of colonic diseases in males with a male to female ratio of 1.4:1 and age range of two years to 84 years was observed. Out of 25 patients diagnosed with colorectal carcinoma, $48 \%(n=12)$ were males and $52 \%(n=13)$ were females with a mean age of 55.17 years in men and 59.46 years in females. Male and female ratio among cancer groups was $1: 1.08$. Total $36 \%(n=9)$ were diagnosed with cancer before the age of 50 . Out of these nine cases, $6(66.7 \%)$ were males and $3(33.3 \%)$ were females. The male and female ratio in younger and older age groups were 2:1 and 1:1.7 .17(68\%) of the lesions were left sided and $8(32 \%)$ were right sided. Below age 50 , left to Right sided lesions in males were 2:1 and in females 1:2. However, above 50 years the ratio among proximal and distal lesions were 5:1 in males and 2.3:1 in females. A statistically significant association was seen between the growth $(p=0.000)$ and per rectal bleeding $(p=0.006)$ with carcinoma.

\section{Conclusion}

The most prevalent lesion in colorectal biopsies was non-specific colitis followed by carcinoma colon. The incidence of colorectal carcinoma is on rise in Nepalese society. Although colorectal carcinoma is more common in older age group the incidence are also increasing among young especially among women.

\section{KEY WORDS}

Colonoscopy, colorectal carcinoma 


\section{INTRODUCTION}

A large portion of human diseases are attributed to the disorders of colon. Colon is the primary host to many neoplasms. The spectrum of colonic lesions span from infectious, idiopathic, inflammatory diseases, polyps, motility disorders and colorectal tumors. All these lesions often require colonoscopic biopsies for their conclusive diagnosis. ${ }^{1}$ The various conditions of colon are segregated for diagnosis on the basis of four main categories like mucosal architecture, lamina propria cellularity, inflammatory cells infiltration and epithelial abnormalities. ${ }^{2}$

Epithelial tumors of intestine accounts for a large cause of mortality and morbidity. Colorectal cancers holds second position in women and third position in men in terms of mortality. ${ }^{3}$ In South Asian countries the incidences are comparatively low. However, they are reported to be increasing in economically developing countries including Nepal. ${ }^{4}$ Furthermore, epidemiological change of colorectal cancer has been observed in the past with increased incidence among young. Similarly, right shift in the colonic diseases has also been reported. ${ }^{5,6}$

There are limited studies available on the subject in Nepal. This hospital based prospective study has been undertaken to investigate the distribution of various colonic lesions and help in the future planning of disease strategies.

\section{METHODS}

This study was conducted from July 2011 to July 2012 at Dhulikhel Hospital. The ethical approval was taken from the Kathmandu university Ethical Review Committee. Patients with colonic lesions, presenting at Dhulikhel Hospital were examined by flexible colonoscopy after taking informed consent. Colonic biopsies were received from the required mucosal sites. During the endoscopic procedures, relevant clinical history, including age and sex and the positive endoscopic findings related to the patient were taken into the request form.

The biopsy specimen obtained in the Department of Pathology were fixed in $10 \%$ buffered formalin. The sections of 3-5 micron were prepared and stained with routine Hematoxylin and Eosin stain. Other special stains like Periodic Acid Schiff (PAS), Mucicarmine, Ziehl Nelson (ZN) and Giemsa were also used for the respective specific lesions.

The slides were examined by the pathologists of the department and reports were dispatched. Biopsies of adequate size and from the representative sites were included in the study. Similarly, inadequate biopsies were excluded from the study. Patients who had inflammatory or infective/non specific colitis were distinguished from particular diseases like Tuberculosis, Ulcerative colitis, Foreign body granulomas. Biopsies of benign polypoid lesions were segregated from malignant tumors. The cancer patients were segregated in the young age group belonging to less than 50 years and older age group when equal to or above 50 years of age. Chi Square test was used to test the association between colorectal carcinoma and age, gender, site and presenting symptoms.

\section{RESULTS}

A total of 126 colonic biopsies were obtained during the one year study period.

Table 1. Shows the histomorphological profile of different biopsies.

Table 1. The nature of colonic lesions determined by histopathology.

\begin{tabular}{|ll|}
\hline Diagnosis & Frequency \\
\hline Chronic Non Specific inflammation & $34(27 \%)$ \\
\hline Carcinoma Colon & $25(19.8 \%)$ \\
\hline Non neoplastic Polyps & $21(16.7 \%)$ \\
\hline Granulomatous Lesion & $14(11.1 \%)$ \\
\hline Neoplastic Polyps & $8(6.3 \%)$ \\
\hline Ulcerative colitis & $4(3.2 \%)$ \\
\hline Others & $19(15.1 \%)$ \\
\hline Normal & $1(0.8 \%)$ \\
\hline
\end{tabular}

A higher frequency of colonic diseases in males with a male to female ratio of 1.4:1 and age range of 2 years to 84 years were observed. Mean age group was of 47.5 years. The highest frequency of diagnosis was chronic nonspecific inflammation followed by colorectal carcinoma, nonneoplastic polyps, neoplastic polyps, Granulomatous lesions (Including Tuberculosis and Crohns Disease). Others included: Acute Focal colitis, Eosinophilic colitis. The various presentation of the patients are represented in Table 2.

Pain abdomen was the commonest symptom irrespective of age and sex.

The frequency of symptoms patients presented were pain abdomen (38.1\%), growth $(23.1 \%)$, bleeding per Table 2. Symptoms of the patients with colonic lesions.

\begin{tabular}{|llll|}
\hline Variables & & Frequency & Percentage (\%) \\
\hline Growth & Male & 19 & 24.3 \\
\hline \multirow{2}{*}{ Per Rectal bleeding } & Female & 10 & 19.2 \\
\hline & Male & 7 & 9.5 \\
\hline Anemia & Female & 5 & 9.6 \\
\hline \multirow{2}{*}{ Altered bowel habit } & Male & 1 & 1.4 \\
\hline \multirow{2}{*}{ Diarrhoea } & Female & 2 & 3.8 \\
& Male & 5 & 6.8 \\
\hline Pain abdomen & Female & 3 & 5.8 \\
\hline & Male & 2 & 2.7 \\
\hline & Female & 4 & 7.7 \\
\hline & Male & 31 & 41.9 \\
\hline
\end{tabular}


Table 3. Comparison of frequency of colorectal carcinoma according to age groups, sites and symptoms.

\begin{tabular}{|lcc|}
\hline Demographics & $\begin{array}{c}\text { Demographic Less } \\
\text { than } \mathbf{5 0} \text { years }(\mathbf{n}=\mathbf{( 9 )}\end{array}$ & $\begin{array}{c}\text { Equals to or more } \\
\text { than } \mathbf{5 0} \text { years }(\mathbf{n}=\mathbf{1 6})\end{array}$ \\
\hline Left sided lesion & 5 & 12 \\
\hline Right sided lesion & 4 & 4 \\
\hline Growth & 6 & 11 \\
\hline Per rectal Bleeding & 2 & 4 \\
\hline Altered Bowel Habits & 0 & 2 \\
\hline Anemia & 0 & 1 \\
\hline Diarrhea & 1 & 0 \\
\hline Abdominal Pain & 0 & 1 \\
\hline
\end{tabular}

rectum(9.5\%), altered bowel habits(6.3\%) , diarrhea(4.8\%) and anemia (2.3\%).

Out of 25 patients diagnosed with colorectal carcinoma, $48 \%$ $(n=12)$ were males and $52 \%(n=13)$ were females. The age distribution among males were 24-84 years with a mean age of 55.17 years and among females were $20-80$ years with a mean age of 59.46 years. Overall Male to Female ratio among cancer groups was 1:1.08. The patients in the study included were grouped under the broad headings of younger ( less than 50 years) and older group( equal to or above 50 years). In the series, total $36 \%(n=9)$ were diagnosed with cancer before the age of 50 . Out of these 9 cases, 6(66.7\%) were males and 3(33.3\%) were females. Similarly, out of $16(54 \%)$ of older age group 6(37\%) were male and $10(63 \%)$ were females. The $\mathrm{M}: \mathrm{F}$ ratio in younger and older age groups were 2:1 and 1:1.7 respectively suggesting male predominance in younger age group and female in older age group. 17(68\%) of the lesions were left sided and $8(32 \%)$ were right sided. Among left sided lesions, 8(47\%) were males and 9(53\%) were females. In right sided lesions $3(37 \%)$ were males and $5(63 \%$ were females. Below age 50 , left to Right sided lesions in males were $2: 1$ and in females 1:2. However, above $50 \mathrm{yrs}$ the ratio among proximal and distal lesions were $5: 1$ in males and 2.3:1 in females.

Irrespective of age and sex, the overall commonest symptom was presence of growth. Other modes of presentation were per rectal bleeding, anemia, altered bowel habits, diarrhea and pain abdomen. However, most of the patients had more than one symptom at presentation. A statistically significant association was found between the growth $(p=0.000)$ and per rectal bleeding $(p=0.006)$ with carcinoma. In older age group $69 \%(n=11)$ and in younger age group $(n=6) 67 \%$ presented with the growth. Similarly, in older age group $25 \%(n=4)$ and $22 \%(n=2)$ presented with per rectal bleeding.

\section{DISCUSSION}

In the present study the most common histological pattern was chronic non specific inflammation followed by infective causes like Granulomatous lesion suggestive of Tuberculosis, Crohns disease and Ulcerative colitis. Similarly, our finding of high incidence of chronic non specific inflammation is consistent with findings of Bashir et.al. ${ }^{7}$ Study by Heymann et al suggested the presence of chronic non specific inflammation colon may represent the early stages of inflammatory bowel diseases like Ulcerative colitis or Crohns Disease. ${ }^{8}$ In agreement with other studies conducted at National Academy of Medical Sciences ( NAMS), Nepal, the incidence of Ulcerative Colitis are on rise in Nepal. ${ }^{9}$ According to Sharma VK et al out of 44 patients with chronic diarrhea and abdominal pain improvement of symptoms were noticed when treatment were taken along the line of ulcerative colitis suggesting the presence of ulcerative colitis in Nepal. ${ }^{9}$ Our study had the diagnosis of Ulcerative Colitis as fifth common lesion. However, this finding is not comparable to that of Qayyum et al ,where they presented it as second common lesion in colonoscopic biospies. ${ }^{10}$ Since the community based studies on epidemiology of colonic biopsies are sparse further investigations on this is appreciated.

This study has used a comprehensive approach in estimating risks of colorectal carcinoma across the age, between the sexes, sites and also the precision of symptoms in the diagnosis of colorectal carcinoma (CRC).

Colorectal cancer screening guidelines suggest regular screening beginning at the age of 50 years and continuing until the age of 75 years as the key to preventing colorectal cancer provided no associated risk factors mainly family history present. Though colorectal carcinoma is a disease of old age, now a days more younger patients are being suffering. In our study, $36 \%$ of the patients were below the age of 50 years. Though this study is not in consistent with study by Kansakar et al in Nepal showing $28 \%$ of colorectal carcinoma in younger age group. ${ }^{11}$ However, it is consistent with other findings in India and Egyptian studies where it was ranged between $35.6 \%-40 \% .^{12-14}$

Similarly, International trends in the incidence of colorectal carcinoma show mixed data ranging from $2-34 \%{ }^{15}$ This increasing trend in Nepal resembles the epidemiological character of developing countries which show higher incidence in the younger age groups. This young age group incidence can be attributed to the young age structure of the underdeveloped or developing countries population pyramid. In the last 15 years the age structure of Nepal has become different with children of 15 years or younger lowered to $36.7 \%$, those between $15-59$ years has increased to $54.2 \%$ and those of 60 years or above make only $9.1 \%$ of the population. ${ }^{16}$

Another possible explanation to this may be due to accelerated carcinogenic pathway due to environmental and genetic susceptibility. ${ }^{17} \mathrm{~A}$ study by Pratt et al revealed exposure to agricultural and other chemicals used in growing rice and soya beans as the major environmental carcinogen responsible for colorectal carcinoma among adolescents. ${ }^{18}$ Since agriculture is the main occupation 
of Nepalese it could be responsible in context of Nepal as it aids to $38 \%$ of economy. ${ }^{19}$ Two main types of familial colorectal carcinoma are familial adenomatous polyposis (FAP) and Lynch syndrome also called Hereditary nonpolyposis colorectal cancer (HNPCC). ${ }^{20}$ Individuals with FAP results from a germline APC mutation and HNPCC from microsatellite instability. ${ }^{20}$ Individuals with FAP and HNPCC have $80 \%$ to $100 \%$ chances of developing colorectal carcinoma. ${ }^{20}$ Studies have shown that $8.1 \%$ and $10 \%$ of the young individuals with Colorectal carcinoma had FAP. ${ }^{21,22}$ MacGillivary et al also found HNPCC in $2.1 \%$ of young individuals with carcinoma. ${ }^{22}$ However, no studies have been performed in Nepal regarding the environmental and genetic factors so far.

Our study has shown a ratio of male to female in the younger and older age groups as 2:1 and 1:1.7 respectively indicating male preponderance in the younger age group and female in the older. It may be due to the protective role of estrogen against the development of colorectal carcinoma. But there are conflicting data regarding the importance of sex hormones in the development of colorectal cancer. Some studies indicate endogenous estrogen or hormone replacement therapy reduce the risk of colorectal carcinoma whereas others indicate circulating estrogens levels are positively linked with the risk of colorectal cancers. ${ }^{23}$ The study performed by Womens Health Initiative (WHI) and New York University Womens Health reported high endogenous estrogen level are associated with 1.5 folds or $60 \%$ increased risk of colorectal cancer by exhibiting proliferative effects in colorectal tissue and in colorectal cancer cell lines. ${ }^{24,25}$ In disagreement to this, studies by Nanda et al and Paganinin have recorded that Hormone replacement therapy are associated with reduced risk of colorectal carcinoma among post menopausal women. ${ }^{26,27}$ Fisher et al in his study suggested that estrogen receptor B predominantly present in colonic mucosa is responsible for preventing malignant change of colonic epithelial cells and their reduction have been shown in colonic adenocarcinoma. ${ }^{28}$ Though different mechanisms how estrogen is responsible for causing or preventing colorectal tumorogenesis have been proposed, none of them have been really elucidated.

When comparing colorectal carcinoma in different locations, the percentage of right sided carcinoma in the present study is on rise. Since the 1980s there has been a persistence increase in the right sided colon cancers as evidenced by other studies. ${ }^{29,30}$ According to our study, the increase is more pronounced towards right side especially in females of younger age group. This suggest the changing scenario of the age, sex and site distribution. Changing dietary habits ( high fat and low fibers), increase incidence of smoking among females, obesity and less physical activity may be responsible. ${ }^{31}$ This is comparable with other studies of higher right shift among women than men. ${ }^{32}$

In our study, poorly differentiated adenocarcinoma was the most common histological variant irrespective of age group. It is also supported by other series. ${ }^{33}$ But the analysis of histological features by the Egyptian studies revealed mucinous /signet ring variant as the commonest in younger age group. ${ }^{13,34}$ This type of tumor in the young has been associated with an increased risk of local recurrence.

Interestingly, in this series, the commonest mode of presentation irrespective of age group was growth which is actually one of the late presentations of the disease process. The second commonest was per rectal bleeding. This is in contrast to the findings of Halder et al in which the commonest presentations varied according to the age groups. ${ }^{12}$ In his study, the young group presented mainly with pain abdomen and old age group mainly with weight loss. Similarly, in other studies per rectal bleeding has been the main symptom. ${ }^{35,36}$ The presentation of young groups with delayed symptoms like growth could be due to delay in diagnosis or bad access to the health care system. In Nepal the national health care system cover only a minority of population with average consumption of health care being only 20 dollars per year. ${ }^{16}$ Likewise, the influence of the environmental or genetic causes cannot also be ignored. It is very important to detect the disease in early stages to improve the survival. However, in Nepal the various gastrointestinal infections are frequent and the symptoms may be interpreted as those of non cancerous conditions. People also have easy access to broad spectrum antibiotics which can be easily bought in pharmacies without the prescriptions which may cause delay in seeking medical help. Hence, patients delay and poor knowledge regarding the cancerous lesions have to be acknowledged.

\section{CONCLUSION}

Although colorectal carcinoma was once primarily observed in developed countries, the epidemiological transition with increase burden are evolving in developing countries like Nepal. ${ }^{37}$ Our study indicates a shift in the incidence of colorectal carcinoma towards young age group especially among women. It also reinforces the trend of migration of colonic cancers towards the right. Urbanization and change of living habits may have had this affect to the increasing incidence among people of Kavre district. It is thus important to investigate further on this issue taking into account the genetic correlation and environmental influence and the effect of estrogen in females.

\section{REFERENCES}

1. Singh $H$, Turner $D$, Xue L, Targownik $L E$, Bernstein $C N$. Risk of developing colorectal cancer following a negative colonoscopy examination. JAMA. 2006; 295(20): 2366-73.

2. Guidelines for the initial biopsy diagnosis of chronic inflammatory bowel disease. BSG- A structured approach to colorectal biopsy assessment. Guidelines in Gastroenterology August 1997. 
3. Juilam T, Cywong B, Mulder CJJ, Salvador A, Hui WM, Lam AK et al. Increasing prevalence of advanced colonic polyps in young patients undergoing colonoscopy in a referral academic hospital in Hongkong. World J Gastroenterol. 2007; 13(28): 3873-77.

4. Pradhananga K, Baral M, Shrestha B. Multi institutional hospital -based cancer incidence data for Nepal - an initial report. Asian Pac J Prev. 2009; 10: 259-62.

5. Cucino C, Buchner A, Sonnenberg A. Continued rightward shift of colorectal cancer. Dis Colon Rectum. 2002; 45 1035-40.

6. larsen K, Bray F. Trends in colorectal cancer incidences in Norway 1962- 2006; an interpretation of the temporal patterns by anatomic subsite. Int J Cancer. 2010; 126: 721-32.

7. Bashir S, Nadeem R, Khan NR, Suleman BA, Qureshi GR. Histopathological Analysis of 1000 Colorectal Biopsies in Two Years in Shaikh Zayed Hospital, Lahore. APJCP. 2012;13(3) : 975-8.

8. Heymann B, Perman JA,Ferrell LD, Thaler MM. Chronic nonspecific inflammatory bowel disease of the cecum and proximal colon in children with grossly normal appearing colonic mucosa diagnosis by colonoscopic biopsies. Pediatrics 1987; 80(2): 255-61.

9. Paudel SMR, Sharma VK. Ulcerative colitis- is it the clinical problem in Nepal? PMJN. 2007; 7(2): 1-6.

10. Qayyum SA, Sawan SA. Profile of colonic Biopsies in King Abdul Aziz University Hospital, Jeddah. J Pak Med Assoc 2009;59(9):608-11.

11. Kansakar P, Singh Y. Changing Trends of Colorectal carcinoma among Nepalese Young Adults. APJCP 2012;13: 3209-12.

12. Halder SK, Bhattacharjee PK, Bhar P, Pachaury A, Biswas RR, Majhi T et al. Epidemiological, clinico-pathological profile and management of colorectal carcinoma in a Tertiary referral centre of Eastern India. JKIMSU 2013;2(1) : 45-50.

13. Alici S, Aykan NF, Sakar B, Gulistan B, Kaytan E, Topouz E. Colorectal carcinoma in young patients : characteristics and outcome. TJEM 2013; 199(2) : 85-93.

14. Quah HA, Joseph R, Schrag D, Shia J, Guillen JG. Young age influences treatment but not outcome of colon cancer. ASO. 2007; 14: 2765-95.

15. Fairley TL, Cardinez CJ, Martin J. Colorectal cancer in US adults younger than 50 years of age,1998-2001. Cancer. 2006;107: 1153-61.

16. Nepal living standards survey. Statistical report,nr 1. Central Bureau of Statistics, National Planning Commission, Government of Nepal, Nepal: 2011.

17. Morris EJ, Penegar S, Whitehouse LE, Quirke P, Finan P, Bishop DT. A retrospective observational study of the relation between family history and survival from Colorectal Cancer. Br J Cancer 2013;108(7): 1502-7.

18. Pratt CB, Rivera G, Shanks E. Colorectal carcinoma in adolescents implications regarding eitology. Cancer 1977; 40 : 2464-72.

19. National Population Report, Government of Nepal, Ministry of Population and Health, Population Division, Ramshahpath, Kathmandu, Nepal: 2011.
20. Mc Cart AE, Vickaryous NK, Silver A. Apc Mice : Models, modifiers and mutants. Pathology Res Pract. 2008 ; 204 : 479-90.

21. Martin EW, Joyce S, Lucas J. Colorectal carcinoma in patients less than 40 years of age : pathology and prognosis. Dis Colon Rectum. 1981; 24: $25-8$.

22. MacGillivray DC, Swatz SE, Robinson AM. Adenocarcinoma of the colon and rectum in patients less than 40 years of age. Surg Gynecol Obstet. 1991;172 : 1-7.

23. Hoda HE. Colorectal carcinoma in upper Egypt, Does age make a difference in survival. Med J Cairo Univ. 2010;78(2) : 145-50.

24. Gunter MJ, Hoover DR, Yu H. Insulin, insulin -like growth growth factor-1, endogenous sex hormones and risk of colorectal cancer. Cancer Res. 2008; 68(1) : 329-37.

25. Clendenen TV, Koenig KL, Shore RE. Postmenopausal levels of endogenous sex hormones and risk of colorectal cancer. Cancer Epidemiol Biomatkers Prev. 2009;18(1) : 275-81.

26. Nanda K, Bastian LA, Hasselblad V, Simel DL. Hormone replacement therapy and the risk of colorectal carcinoma : A meta- analysis. Obstretics and Gynaecology. 1999; 93(5): 880-8.

27. Paginini $H$. Estrogen replacement therapy and colon cancerrisk in elderly women. Dis Colon Rectum. 1999; 42( 10) : 1300-5.

28. Fisher M, Fisher L, Waxman W, Fisher A. Changing trends in colorectal cancer: possible cause and clinical implications. Health. 2010; 2(8) : 842-9.

29. Lin JT, Wang WS, Yen CC, Liu JH, Yang MH, Vhao TC. Outcome of colorectal carcinoma in patients under 40 years of age. J Gastroenterol Hepatol. 2005; 20( 6) : 900-5.

30. Zervoudakis A, Strickler HD, Park Y, Xue X, Hollenbeck A, Schatzkint A. Reproductive history and risk of colorectal carcinoma in postmenopausal women. JNCI 2011;103(10): 70-6.

31. Johnson JJ, Mukhtar H. Curcumin for chemoprevention of colon cancer. Cancer Letters. 2007,255:170-181.

32. Meguid RA, Slidell MB, Wolfgang $C$. Is there any difference in right sided versus left sided colon cancer? Ann Surg Oncol 2008; 15: 238894.

33. Obrand DI, Gordon PH . Continued change in the distribution of colorectal carcinoma. Be J Surg 1998; 85: 246-8.

34. Saltzstein SL, Behling CA. Age and time factors in the left to right shift of the subsite of colorectal adenocarcinoma : a study of 213,383 cases from California Registry. Clin Gastroenterol. 2007; 41: 173-7.

35. Gul A, Alam SI, Aslam R, Alam W. Colorectal carcinoma; Frequency of common histological types in patients below 40 years of age presenting to Tertiary care Hospital. Professional Med J. 2011; 18(4) : 566-70.

36. Kenawi MM, El-saied A, El- Bolkainy N, Bahyeldeen HN. Relative frequency of gastrointestinal malignancies at $\mathrm{NCl}$ during 14 years (1976-1989). Med J Cairo Uni. 1990;58: 35-41.

37. Ferlay J, Shin H, Bray F, Forman D, Mathers C, Parkin DM. Estimates of worldwide burden of cancer in 2008: GLOBOCAN 2008. Int J Cancer 2010,127:2893-2917. 